\title{
LOS AFROBRASILEÑOS Y LA FORMACIÓN DE SUS PRIMERAS OR- GANIZACIONES EN CONTRA DEL PREJUICIO Y LA EXCLUSIÓN
}

Mónica Velasco Molina*

\begin{abstract}
RESUMEN: La abolición de la esclavitud en Brasil se produjo en un periodo en el que las teorías raciales estaban en boga, lo cual tuvo un gran impacto en las élites brasileñas. Sin embargo, los africanos y afrobrasileños libres lograron, a pesar de los prejuicios, de los discursos que negaban la segregación de los negros e incluso de las diferencias existentes dentro de la comunidad negra, fundar organizaciones como la "prensa negra" y "Frente Negra Brasileña" que enfrentaron la discriminación y exhibieron el racismo fuertemente arraigado dentro de la sociedad brasileña.
\end{abstract}

Palabras Clave: Brasil, Prensa negra, Frente Negra Brasileña, Democracia racial.

ABSTRACT: Abolition of slavery in Brazil was enacted in a period when racial theories were at vogue. It had an important consecuences within brazilian elites. Nevertheless, free Africans and afrobrazilians showed that, inspite of the prejudices, the speeches that were denying the segregations of the blacks and even the existing differences inside the black community, there manage to found organization such as "prensa negra" and "Frente Negra Brasileña" that faced discrimination and exhibited the racialism strongly established inside the Brazilian society.

Key words: Brazil, Prensa negra, Frente Negra Brasileña, Racial Democracy.

\section{INTRODUCCIÓN}

A finales del siglo XIX, la sociedad brasileña experimentó tanto el debilitamiento como la posterior caída del sistema esclavista. Dicho proceso casualmente también se vio acompañado del ascenso del sistema republicano y, paradójicamente, de la entusiasta acogida de los intelectuales brasileños respecto del pensamiento racial gestado en Europa a finales del siglo XIX y principios del XX.

* Becaria del proyecto PAPIIT "Africanos y afrodescendientes en México y el Caribe", CIALC-UNAM (monvelmol@yahoo.com.mx / papiitafro@gmail.com). 
Estas últimas ideas tuvieron como premisa que dentro de la sociedad existían diferencias marcadas por las características físicas, inclusive por el tamaño y la forma del cráneo o el peso del cerebro. En lo que se refiere al color de la piel, el blanco fue colocado en el lugar más alto de la sociedad, mientras el negro siempre fue considerado como inferior. Esto último, como ya señalé, tuvo una gran acogida entre la intelectualidad brasileña de la época. ${ }^{1}$

El impacto de estas teorías permitió justificar las diferencias entre los ciudadanos, y como consecuencia también la exclusión del afrobrasileño dentro de su propia sociedad. En este contexto, el objetivo de las siguientes líneas es demostrar que así como los africanos y los afrobrasileños generaron diversas estrategias de resistencia durante el periodo esclavista, en los años inmediatamente posteriores a la abolición de la esclavitud y, consecuentemente frente al prejuicio racial, éstos continuaron luchando por ser reconocidos y respetados dentro de la sociedad brasileña.

A fin de conseguir tal propósito, presento dos de las primeras organizaciones fundadas por los brasileños negros que buscaron, con diferentes repercusiones y alcances, hacerle frente a la segregación racial. La primera de ellas es la llamada "prensa negra". Su valor radica en que permite observar tanto la visible heterogeneidad existente dentro de la comunidad afrobrasileña, como ser la primera tentativa que buscó resaltar los prejuicios a los que ha estado sujeto el negro en Brasil.

En segundo lugar, se analiza "Frente Negra Brasileña", organización fundada en la década de los años treinta del siglo XX. El análisis de esta agrupación ayuda a comprender los problemas y la manera de enfrentarlos por la mayoritaria comunidad negra. Al mismo tiempo, cómo tanto la ideología, la democracia racial e inclusive la inmigración europea, tuvieron diferentes repercusiones al interior de estados que han atravesado por diversos procesos político-sociales y económicos, como São Paulo y Bahía.

1 Para conocer con detenimiento estos debates véase Renato da Silveira, "Os Selvagens e a massa. Papel do racismo científico na montagem da hegemonia occidental", AfroÁsia, núm. 23, Centro de Estudios Afro-Orientales/UfBA, 2000, pp. 87-144. 


\section{LA PRENSA NEGRA}

La contradicción latente entre la situación formal del negro liberto, a la que cada día se vio éste expuesto, se manifestó en todos los ámbitos de la vida cotidiana y queda perfectamente evidenciada, por ejemplo, en los grandes periódicos de la época en donde la comunidad negra es invisibilizada, además de ser sujeta a toda clase de insultos y adjetivaciones negativas. Como respuesta a esta situación, a finales del siglo XIX y principios del siglo XX se organizó la "prensa negra".

Para José Correia Leite, fundador del periódico Clarim de Alvorada, el surgimiento de esta prensa se debió a que

la comunidad negra de São Paulo vivía — como una minoría que era — con sus entidades y sus clubes. Por lo que había necesidad de contar con un vehículo que anunciara los acontecimientos sociales que tenían en la comunidad [...]. Como era natural, la prensa blanca no iba a cuidar de dar información sobre sus actividades. De ahí surgió la prensa negra [...] Aunque no nació como un movimiento ideológico; un movimiento de lucha de clases. ${ }^{2}$

Miriam Ferrara propone tres etapas para comprender el proceso por el cual atravesó la "prensa negra":

1) 1915 a 1923. La línea editorial tuvo como principal objetivo informar sobre eventos sociales, literatura y todo aquello que fuera de interés para la comunidad afrobrasileña. ${ }^{3}$ Aunque también se han podido localizar periódicos que consignaron entre sus páginas denuncias contra el racismo, lo que en sí mismo representó ya un avance en la politización de la comunidad negra, lo que preparó el escenario para una mayor y más clara movilización en los siguientes años.

2 José Correia Leite, grabado el 15 de julio de 1975. Cita extraída de Clóvis Moura, "Formas de resistência do negro escravizado e do Afro-descendente", en Kabengele Munanga [org.], História do negro no Brasil. O negro na sociedade brasileira: resistencia, participação, contribuição, Brasilia, Fundação Cultural Palmares, 2004, p. 45.

3 Petrônio Domingues, A Nova Abolição, São Paulo, Selo Negro, 2008, p. 28. 
2) 1924 a 1937. Se inició con la fundación del ya mencionado periódico Clarim de Alvorada, que tuvo en su fundamento llevar el discurso contra el racismo. Esta fase culminó en 1937 con el establecimiento de la dictadura de Vargas, conocido como Estado Novo, durante el cual fue coartada toda libertad de expresión y asociación.

Durante este periodo trascendió la idea de informar pero también denunciar el racismo. La meta fue unir a la comunidad negra, fortalecerla, demandar el cumplimiento de sus derechos y exigir su participación dentro del conjunto de la sociedad brasileña.

Las asociaciones fundadas en ese momento crearon sus propios periódicos, en donde recogieron y publicaron los debates realizados al interior de ellas. La máxima expresión fue la publicación de $A$ Voz da Raça, medio informativo de la organización Frente Negra Brasileña. Esto "aconteció en una época de aguzado prejuicio respecto del color y de la lucha de clases, hechos que llevaron a los negros a transformar el contenido de sus periódicos que pasaron a manifestarse priorizando sobre el primer problema". ${ }^{4}$

3) El último periodo inició en 1945, con el proceso de redemocratización y la fundación del periódico Alvorada, culminando en 1963. Los años abarcados por esta tercera fase estuvieron marcados por muy diversas movilizaciones políticas, alianzas con partidos políticos, amén de la búsqueda por colocar candidatos a puestos de elección popular. ${ }^{5}$

Por otra parte, desde el siglo XIX, diversos periódicos comenzaron a surgir. Entre ellos el paulista A Pátria [1889] y el gaucho O Ejemplo [1892], que incorporaron en sus páginas la denuncia contra las humillaciones sufridas por negros y mulatos. ${ }^{6}$ Otros periódicos fueron Novo Horizonte; Princesa do Norte; $O$ Getulino, en Campinas; $O$ Patrocínio; $O$ Paulistano; Brinco de Princesa; 28 de setembro, todos editados en São Paulo. En Río Grande do Sul surgió A Vanguarda y A Cruzada.

4 Moura, op. cit., p. 48.

5 Domingues, op. cit., p. 29.

${ }^{6}$ Flávio dos Santos Gomes, Negros e política (1888-1937), Río de Janeiro, Jorge Zahar Editor Ltda., 2005 (Col. Descubrindo o Brasil), p. 28. 
En São Paulo floreció el mayor número de publicaciones. La razón fue que dado el impulso económico originado por la producción cafetalera con su consecuente industrialización y la preferencia por el inmigrante europeo, hizo que la situación de exclusión y racismo en contra del negro se presentara ahí de forma más evidente. Así, la propia dinámica social generó dentro de la comunidad negra la necesidad de hacerse de espacios de información y de agrupación.

El primer periódico en utilizar la idea de "clase de color" fue el periódico $O$ Baluarte, editado por el Centro Literario de los Hombres de Color, en Campinas. El término definió tanto al público al que iba dirigido como hacer referencia a quienes lo producían. Es interesante notar que no se utilizó la palabra negro. La razón es que durante esa época tal adjetivo tuvo connotaciones ofensivas, haciendo políticamente incorrecto su uso. ${ }^{7}$

La cantidad de periódicos permitió un diálogo más abierto entre las diferentes organizaciones y el público al cual estaban dirigidos. Generó una mayor participación y colocó en el centro de la discusión los problemas que aquejaban al negro, así como sus necesidades. Esto proporcionó una mayor fuerza al interior de la comunidad negra.

El impacto de esta prensa fue tan importante que incluso permitió tender un diálogo en el nivel internacional con otras organizaciones, especialmente de Estados Unidos y de algunos países del Caribe. Las ideas que circularon fueron "sobre identidades raciales, proyectos y estrategias de acción". ${ }^{8}$ Con esta dinámica comenzó un interesante diálogo entre José Correia Leite y el jamaiquino Marcus Garvey sobre las ideas del panafricanismo.

Entre los periódicos afrobrasileños tuvo gran difusión el movimiento negro de Estados Unidos, lo que permitió enriquecer el debate que se comenzaba a gestar dentro de la propia comunidad afrobrasileña. Aunque, como recuerda Flávio dos Santos, no todos sintieron inclinación por esas ideas, e irónicamente acusaron a sus promotores en Brasil de querer importar no sólo un movimiento, sino un modelo racista. ${ }^{9}$

\footnotetext{
${ }^{7}$ Domingues, op. cit., p. 47.

${ }^{8}$ Santos Gomes, op. cit., p. 41.

${ }^{9}$ Ibid., p. 42.
} 
Entre las estrategias implementadas para recaudar recursos económicos y poder sostener estos periódicos se encuentran: las rifas, las fiestas así como los recursos otorgados por los propios miembros de las asociaciones negras a las que representaban. Muchos de sus editores absorbieron la mayor parte de los gastos con la idea de que la emisión de los periódicos fuese más o menos regular.

Aunado a lo anterior, dado que la principal finalidad radicó en sostener un espacio de información y diálogo y no el lucro, muchos de los ejemplares fueron regalados. Todos estos elementos explican la irregularidad y la precariedad en la emisión de esta prensa.

A pesar de los diversos problemas a los que se enfrentó, la creación de espacios para difundir las propias ideas de la comunidad negra resultó un elemento clave en la formación de las subsecuentes organizaciones que tuvieron un esquema más complejo y de mayor alcance. Por lo tanto, dentro de la construcción de entidades de lucha y combatividad formadas por los afrobrasileños para ser incluidos dentro de la sociedad brasileña, la "prensa negra" debe ser considerada como un eslabón fundamental.

Otra característica de esta prensa fue la modestia de sus tirajes. La excepción fue $O$ Getulino que imprimió hasta 1500 ejemplares..$^{10}$ Esta cifra es considerable, en primer lugar, dado que el contenido de la "prensa negra" fue altamente endógeno; y segundo, el índice de analfabetismo era alto. En São Paulo, a mediados de 1922-1923, según el registro realizado por el servicio militar, más de la mitad de los negros asistentes eran analfabetos; esto es, $51.6 \%$. De éstos $93.4 \%$ sólo había cursado la primaria. ${ }^{11}$ De esta forma, el analfabetismo de la comunidad negra redujo aún más el acceso a esta prensa. Lo anterior indica que el tiraje de $O$ Getulino fue importante.

${ }^{10}$ Domingues, op. cit., p. 37.

${ }^{11}$ Coronel Dr. Arthur Lobo da Silva, "A antropología no exército brasileiro", Arquivos do Museo Nacional, vol. XXX, Río de Janeiro, 1928. Citado por Petrônio Domingues, Uma história não contada. Negro, racismo e branqueamento em São Paulo no pósabolição, São Paulo, Senac, 2004, p. 156. 
Mención especial merece $O$ Clarim de Alvorada, fundado en 1924. Fue el único, dentro de la "prensa negra", que para 1930 ya circulaba por varias ciudades de São Paulo, como Santos, Botucatu, Bauru, Sofocaba y Río Claro. Tuvo ediciones en Río de Janeiro y Bahía. Fue solicitado por la biblioteca de Recife, en Pernambuco. Su tiraje mensual alcanzó hasta 2000 ejemplares. ${ }^{12}$ Además, abrió espacios para que la comunidad lectora publicara sus cuentos, poesías y bromas.

Todos estos periódicos fueron sostenidos por la élite negra que desempeñaba actividades como periodistas, profesionales liberales, técnicos, empleados públicos, etc. Cuando me refiero al término "élite" no significa que fueran propietarios de los medios de producción, sino que al ser los alfabetizados, se configuraron como los dirigentes políticos de la comunidad, por supuesto se vieron aceptados por los blancos, al reproducir los valores ideológicos de la clase dominante. ${ }^{13}$

Esto último se reflejó en el lenguaje puritano que predominó en los periódicos. La idea era transmitir al lector los buenos hábitos y las mejores formas de comportamiento, como alejarse de las bebidas alcohólicas; tener en las fiestas bailes de salón al estilo europeo, rechazar los ritmos con influencia afro; sin olvidarse de persuadir a sus lectores de alejarse de las religiones de matriz africana; y naturalmente, ser trabajador, cumplido y responsable.

Tal situación causó, como consecuencia, el alejamiento del resto de la comunidad negra conformada por desempleados, domésticas, prostitutas, quienes continuaron con sus prácticas culturales tales como realizar batuques, samba, capoeira y practicar las religiones de origen africano. Esta parte de la comunidad negra, caracterizada como "plebe" por la "élite" negra, rechazó, como es de suponerse, tajantemente dicho discurso pedagógico.

Las diferencias entre ambos grupos explicitó, una vez más, la gran heterogeneidad de la comunidad negra. Por lo tanto, el discurso de los

${ }^{12}$ Petrônio Domingues, "Uma história não contada...", pp. 36 y 37.

${ }^{13}$ Ibid., pp. 209 y 210. 
periódicos fue el canal que movilizó a la minoritaria élite negra que habitó en las ciudades y que buscó alejarse de los estereotipos negativos de los que era objeto el negro, incluso aceptando y adoptando formas de comportamiento de la sociedad que los inferiorizaba. Desde luego, adjudicó a los modelos europeos las connotaciones de modernidad, belleza y elegancia. Los siguientes anuncios del periódico Clarim d'Alvorada y Folha da Manhã son ilustrativos:

Uma invenção maravilhosa!

"O cabelisador". Alisa o cabello o mais crespo sem dôr.

Uma causa que até agora parecia impossível e que constituia o sonho

Dourado de millares de pessoas, já é hoje uma realidade irrefutavel.

Quem teria jamais imaginado que seria possivel alisar o cabello, por mais crespo que fosse, tornando-o comprido e sedoso?

Graças à maravilhosa invenção do nosso "CABELISADOR", consegue-se em conjuncto com duas "Pastas Magicas", alisar todo e qualquer cabello, por muito crespo que seja.

Com o uso deste maravilhoso instrumento, os cabellos não só ficam infallivelmente lisos, mas tambem compridos.

Quem não prefere ter uma cabelleira lisa, sedosa e bonita em vez de cabellos curtos e crespos? Qual a Pessoa que não quer ser elegante e moderna? Pois o nosso "Cabelisador" alisa o cabello o mais crespo sem dor. ${ }^{14}$

Às damas da elite:

O melhor creme para "esterilizar a cútis", branquear, aderir o pó-de-arroz, impingens, massagens [...] é a pomada Minancora. A mais bela criação dos últimos 50 anos.

Vende-se em todo Brasil. ${ }^{15}$

La primera publicidad hace hincapié en que los patrones de belleza occidentales no sólo eran los mejores, al presentarse además el ideal de poseerlos, como un sueño. Y, por si lo anterior no fuera suficiente, aquellos que gozaran de esas características en automático se tornarían elegantes y modernos. Por su parte, el segundo anuncio, muestra el interés

${ }^{14}$ O Clarim d'Alvorada, São Paulo, 9 de junio, 1929, p. 1, citado en Domingues, “A Nova...", p. 48. Las cursivas son mías.

${ }^{15}$ Folha da Manhã, São Paulo, 5 de enero, 1929, p. 2. Citado en Domingues, "Uma história não contada...", p. 291. 
por cambiar la pigmentación de la piel, dado que el negro, en la sociedad racista, daba a entender que el rechazo era consecuencia de su fealdad. La preocupación por el cambio de color se expresó en la venta de cremas, jabones o cosméticos que prometían tal "milagro", como señalaba el anuncio. Por supuesto lo anterior reflejaba no sólo la negación de la identidad, sino la consecuente alienación a los patrones hegemónicos de la élite brasileña blanca.

Si por un lado se exaltaron patrones de conducta, estilo y belleza europeos, por otro, sus editoriales buscaron crear un sentimiento de orgullo y autoafirmación. Por ejemplo, el periódico $O$ Menelick, fundado en 1915. Su título poseyó un fuerte contenido de lucha y resistencia no sólo en Brasil, sino desde luego también en África, percibiéndose una clara identificación con ese continente. Los propios redactores "afirmaban que todos los negros eran parte de una misma historia de luchas y victorias, a ejemplo de aquel emperador africano". ${ }^{16}$

Otro ejemplo es $O$ Clarim de Alvorada, que reivindicó los derechos de la comunidad afrodescendiente, así como su inserción en la sociedad brasileña. Ese mismo periódico publicó una serie de artículos con la finalidad de movilizar a la población para participar en el Primer Congreso de la Juventud Negra de Brasil (1929). Dicho Congreso tuvo como resultado el Manifiesto de la Gente Negra Brasileña. Documento político que reivindicó la integración absoluta y completa del negro en toda la vida brasileña, así como su formación y aceptación, en todo y en todas partes.

Como se puede observar, los discursos publicados por los periódicos de la comunidad negra reflejaron ambigüedades. Por un lado, se exaltó la figura del "hombre de color" y por otro, se idealizaron los patrones de conducta y de belleza europeos. Sin embargo, no se le puede juzgar de buscar un blanqueamiento o sólo una exaltación de su grupo. Esto sería un análisis parcial y no terminaría por explicar la presencia de ambos discursos.

${ }^{16}$ Wlamyra R. de Albuquerque y Walter Fraga Filho, Uma história do negro no Brasil, Salvador, Centro de Estudios Afro Orientales-Fundação Cultural Palmares, 2006, pp. 260 y 261. Menelick II fue un emperador etiope que en el año de 1896 derrotó a los invasores italianos en la batalla de Adwa. 
En primer lugar, la "prensa negra" debe ser contextualizada a la luz de las ideas gestadas en la época sobre la superioridad e inferioridad de las razas. Los afrobrasileños de clase media, especialmente de São Paulo, se negaron a denunciar abiertamente el prejuicio de raza e incluso, en determinados momentos, buscaron adoptar la idea del blanqueamiento. Esto se debió a que el racismo científico europeo era invocado por el resto de la sociedad cuando la comunidad negra trataba de denunciar el racismo en Brasil.

En segundo lugar, aquella imagen tan difundida de que en Brasil el sistema esclavista fue más benigno, hizo que el país se proyectara como una excepción dentro del resto de las sociedades que practicaban de forma violenta la esclavitud. Esta imagen si bien irreal, logró no sólo permanecer dentro del pensamiento internacional y nacional, sino que además trascendió en el tiempo, modificándola y enriqueciéndola. Las ideas acuñadas por las élites se reforzaban dada su hegemonía en todo el espectro de la vida cotidiana, con lo que alimentaba el discurso de la excepcionalidad en las relaciones sociales.

A partir de esta situación se puede entender que, por ejemplo, O Bandeirante, publicara en 1918: "La culpa no es de los blancos -es nuestra!" 17 Como explica Hanchard,

combinada con las prácticas racialmente discriminatorias en la educación, en el mercado de trabajo y en la cultura popular, ella muestra que los negros brasileños estaban encerrados en un patrón elíptico de opresión racial, en el cual las quejas contra las prácticas discriminatorias raramente se escuchaban, y aún más raramente, fueron abordadas por las élites brasileñas. ${ }^{18}$

En una sociedad en la cual, de forma repetida se enunciaba la presencia de relaciones cordiales, no era posible luchar por erradicar un problema como el racismo, si éste en términos formales no existía. Este discurso, por el contrario, fue fuertemente combatido por los propios edi-

${ }^{17}$ Domingues, “A Nova...”, p. 51.

${ }^{18}$ Michael George Hanchard, Orfeu e o poder. Movimento Negro no Rio e São Paulo (1945-1988), Río de Janeiro, Universidade do Estado do Rio de Janeiro, 2001, pp. 75 y 76 . 
tores cuando se anunciaban las flagrantes formas de discriminación sufridas todos los días y se pronunciaban por una segunda abolición. Las formas de exclusión que los periódicos denunciaron fueron de toda índole y provenían de las instituciones gubernamentales, religiosas y civiles.

Por ejemplo, El Clarim de Alvorada, publicó en 1928, que en el Orfanato Amando de Barros, el señor obispo diocesano, no recibía huérfanos de color. La respuesta del periódico fue de rechazo, declarando que

tal vez quiera todavía ese ilustre patricio que el alma blanca del negro humilde y afectivo deba continuar esclavizada [...]. El catolicismo que es una institución puramente piadosa, y esa norma siempre fue mantenida, no puede ahora lanzar en nombre de uno de sus más legítimos representantes la odiosa idea de separación o prejuicio de color, en una localidad tan adelantada. ${ }^{19}$

La "prensa negra" reflejó la lucha constante entre un discurso hegemónico y uno contra-hegemónico, pero por el momento no permitió una batalla frontal debido al interés por evitar la politización del problema racial. Esto esclarece la presencia de ambos discursos en los periódicos de la comunidad negra. También establece la importancia e impacto que tuvieron estas iniciativas periodísticas al abrir un espacio en donde se confrontaron dos visiones del mismo asunto, permitiendo ser un eslabón fundamental para construir, de forma gradual, la politización del negro frente a sus problemas y en la construcción de futuras organizaciones.

${ }^{19}$ O Clarim d'Alvorada, São Paulo, 21 de octubre, 1928, p. 2, citado en Domingues, "Uma história não contada...", p. 150.

La Iglesia católica en São Paulo fue una de las instituciones que practicó el racismo de forma más evidente en contra del negro. Muchas congregaciones rechazaron de sus orfanatos, escuelas, seminarios y órdenes religiosas a los negros. Existen testimonios que evidencian la actuación de algunos clérigos en contra de los propios feligreses, por ejemplo, doña Risoleta declaró "Yo dejé de ser hija de María por causa de un obispo, Don Barreto. Él dijo que nos pasaría todo para la Hermandad de San Benedito porque Nuestra Señora nunca tuvo hija preta". Domingues, "Uma história não contada...”, p. 149. 


\section{DÉCADA DE LOS TREINTA}

Con la Revolución de 1930, que llevó al poder a Getúlio Vargas, cambió el panorama político en Brasil. Como es de suponerse, una parte de la comunidad negra se entusiasmó con este movimiento, en el que vieron una forma de mejorar su situación de vida. La República no sólo los había dejado desprotegidos en las zonas de mayor industrialización del país, sino que además había privado a la gran mayoría de los negros del derecho de participar en la vida política nacional, al negarle el derecho al voto a los analfabetos y paralelamente no crear espacios y condiciones para alfabetizarlos.

Una vez que Vargas asumió el poder, el régimen defendió la imagen de la excepcionalidad de Brasil en el ámbito de las relaciones sociales, así como la novedosa idea de la existencia de una democracia racial. Estos enunciados se apoyaron, fundamentalmente, en los escritos de Gilberto Freyre.

Contrario al evolucionismo cultural, Freyre fue fuertemente influido por las imágenes positivas de la esclavitud, las cuales tuvieron una gran repercusión en los primeros años de la República. En este ambiente, Freyre encabezó otra idea sobre el afrobrasileño. En su libro Casa Grande \& Senzala, rescató no sólo las relaciones entre amos blancos y esclavas negras sino, además, exaltó el carácter mestizo del país.

De esta forma, el régimen de Vargas hábilmente apuntaló la idea de una democracia racial, que tenía como fundamento y consecuencia, el que la sociedad brasileña implícitamente era tolerante, por lo que la desigualdad al interior de ella venía no de una cuestión racial, sino económica. "Esto permitió que brasileños de clase alta [blanca] promulgaran una igualdad mítica entre los sectores mulato, mestizo y preto $[\ldots]$ ". ${ }^{20}$

De esta forma, el discurso dominante reforzó la idea de la inexistencia del prejuicio y la discriminación racial. Los que cuestionaran la democracia racial serían interpelados con los principios de superioridad e inferioridad de las razas. Es decir, si lo negros no lograban colocarse en una mejor

${ }^{20}$ Darien J. Davis, Afro-brasileiros hoje, São Paulo, Selo Negro, 1999, p. 36. 
posición dentro de la sociedad, que supuestamente no los obstaculizaba en su progreso, la responsabilidad era de los propios afrobrasileños, quienes eran incapaces de incorporarse plenamente a la comunidad debido a las premisas ya establecidas por el darwinismo social. Es de esta forma que los discursos hegemónicos se reforzaron continuamente permitiendo que el statu quo permaneciera sin mayores alteraciones. ${ }^{21}$

A partir de la publicación del libro de Freyre y hasta principios de la década de 1950 tanto la excepcionalidad racial, la democracia racial y la exaltación del carácter mestizo del país fueron los argumentos que predominaron en las visiones de las relaciones raciales en Brasil y en los discursos de las ciencias sociales en los ámbitos nacional e internacional, como en el estudio de Frank Tannenbaum, El negro de las Américas. De esclavo a ciudadano..$^{22}$

El discurso de la élite brasileña tuvo otra razón para reafirmar la idea positiva del mestizaje: si no se podía blanquear a toda la población, entonces era importante proyectar una imagen de que lo era. La cuestión de la igualdad fue sólo parte del discurso.

Estas acciones hacen notar, en primer lugar, las diferentes estrategias empleadas por las élites y la nueva intelectualidad para manipular el discurso y sostener el statu quo dentro de las relaciones sociales. Segundo, proyectó una situación en los niveles interno y externo que no sólo no existía, sino además inmovilizó y vació de contenido político, de manera anticipada, cualquier intento de manifestación en contra del racismo y la exclusión.

\section{Frente NEGRA BRASILEÑA}

Es en el escenario ideológico antes referido que surgió una de las organizaciones más importantes, no sólo en São Paulo, centro de su fundación, sino en varias partes de Brasil, fue Frente Negra Brasileña (FNB).

\footnotetext{
${ }^{21}$ Read Andrews, op. cit., pp. 210 y 211.

${ }^{22}$ Hanchard, op. cit., pp. 74 y 75.
} 
Instituida el 16 de septiembre de 1931, tuvo entre sus fundadores a Arlindo e Isaltino Veiga dos Santos, José Correia Leite, Jayme de Aguiar, Francisco C. Santos, David Soares, Alberto Orlando y Gervásio Morais. Además del Centro Cívico Palmares, el periódico Clarim de Alvorada y otras asociaciones. ${ }^{23}$

En un primer momento esta organización no tuvo una buena recepción por parte de la sociedad. Por un lado, irónicamente se acusó a sus fundadores de racismo a la inversa. Por otro, el racismo de la época expresó sus focos de tensión en la gran prensa cuando comúnmente anunciaba: "Se solicita empleado, pero no queremos de color". ${ }^{24}$ El escenario planteaba un panorama difícil, aunque con el paso del tiempo se ganó la confianza de la sociedad, demostrando que su finalidad era la inclusión del negro en todos los ámbitos de la vida brasileña y no una confrontación con la élite blanca.

El objetivo de Frente Negra, según el artículo primero y tercero de su estatuto fue la

unión política y social de la Gente Negra Nacional, para la afirmación de los derechos históricos de la misma, en virtud de su actividad material y moral en el pasado y para reivindicación de sus derechos sociales y políticos [...] en la comunidad brasileña [...]. Asistencia, protección y defensa social, jurídica, económica y de trabajo de la Gente Negra. ${ }^{25}$

Dentro del estatuto también se previó la formación de cooperativas, escuelas técnicas, de ciencia, de arte y de deporte, con la finalidad de alcanzar sus objetivos. La idea era introducir la cuestión del racismo en el nivel político, al tiempo de procurar que sus miembros alcanzaran mejores condiciones de vida.

${ }^{23}$ Santos Gomes, op. cit., p. 48.

${ }^{24}$ Entrevista a Francisco Lucrécio, en Quilombohoje [org.], Frente Negra Brasileira. Depoimentos, São Paulo, Fundo Nacional da Cultura-Ministerio da Cultura, 1998, p. 38.

${ }^{25}$ Diario Oficial del Estado de São Paulo, São Paulo, 4 de noviembre, 1931, p. 12. Citado en Domingues, “A Nova...”, p. 62. 
La estructura de FNB estuvo compuesta de la siguiente manera: un presidente, quien fue la máxima autoridad y el representante de los frentenegrinos frente a la sociedad brasileña; un gran consejo, compuesto por veinte miembros seleccionados entre los integrantes de FNB y que supervisaban el desempeño de los departamentos; un jefe; un secretario encargado de la correspondencia y de la organización de las reuniones del consejo; y un consejo auxiliar formado por los cabos distritales de la capital. ${ }^{27}$

La organización tuvo un grupo paramilitar integrado por todos los jóvenes frentenegrinos. Su objetivo fue "defender a la Sociedad y a la Patria contra los extremistas". ${ }^{28}$ Los integrantes de este sector recibieron una rígida disciplina. Aunque no usaban armas, fueron entrenados en las artes marciales, en particular, en la capoeira.

Frente Negra Brasileña surgió en un momento de coyuntura, en donde se conjuntó el impacto que tuvo en la economía brasileña la crisis mundial de 1929, en especial en la caída de los precios del café; las transformaciones políticas internas y la migración de afrodescendientes que se trasladaron desde distintas partes del Brasil rural a São Paulo, polo de industrialización del país sudamericano. Esta alta migración interna se aprecia en que para 1920 sólo dos de cada diez brasileños residían en las ciudades, mientras que en 1940 la misma relación fue de cuatro por cada diez brasileños. ${ }^{29}$

De esta forma, tanto los recién llegados a São Paulo como los residentes ya establecidos, encontraron un espacio de instrucción, protección, solidaridad e identificación dentro de la organización. A diferencia de la "prensa negra", FNB buscó acortar la distancia entre los objetivos de la élite negra y las necesidades de la mayoritaria comunidad negra. Pronto contó con millares de miembros y con representaciones en casi todo el interior paulista. Estableció delegaciones en los estados de Río de Janeiro, Bahía, Río Grande do Sul, Espíritu Santo y Minas Gerais, lo

${ }^{27}$ Moura, "História do...", p. 72.

${ }^{28}$ A Voz da Raça, São Paulo, 8 de marzo, 1933, p. 3. Citado por Domingues, “A Nova...”, p. 63.

${ }^{29}$ Mary del Priore y Renato Pinto Valencia, O livro de ouro da História do Brasil, Río de Janeiro, Ediouro, 2001, pp. 324 y 325. 
que le proporcionó una extensa red de información y fortalecimiento al interior y frente al gobierno.

La organización FNB se financió a través de las mensualidades que los miembros y agrupaciones afiliadas aportaban, además de ventas de productos caseros y la realización de festivales. A la sede de FNB asistieron intelectuales blancos para ofrecer conferencias o dar clases, lo que no significó que pudieran adherirse a la organización. ${ }^{30}$

La fuerza que alcanzó FNB fue tan importante, que la credencial emitida por ellos fue avalada por la propia policía, quien al detener a un negro y éste exhibir su credencial era liberado inmediatamente. Como menciona Marcello Orlando, miembro de FNB, "los negros que portaban aquella credencial gozaban en la policía de cierto respeto, una cierta protección [...]. Pasó a ser respetada, incluso, por delegados de policía e investigadores."31

Como el resto de las organizaciones que se formaron en esa época, FNB no fue un movimiento de masas. En realidad su fuerza provino de contar con líderes que tuvieron un perfil de funcionarios públicos o profesionistas que conjuntó la fuerza popular de los sectores negros con movilidad social más limitada, que trabajaba en subempleos y que era mayoritariamente analfabeta. ${ }^{32}$

Sus diferentes actividades propiciaron la creación de diez departamentos. Entre ellos estuvo el de Cultura, que logró formar una escuela con su biblioteca. Los cursos para los niños y los de alfabetización para adultos fueron impartidos por los propios jóvenes frentenegrinos que estudiaban Ingeniería, Biología, Comercio u otras áreas. Como comentó Francisco Lucrécio, secretario de FNB desde 1934, "La escuela fue importante, principalmente cuando FNB profundizó en la cuestión política. Por lo que el negro necesitaba alfabetizarse para obtener su título de elector". 33

El departamento de prensa fue el responsable del periódico $A$ Voz da $R a c ̧ a$, lanzado por primera vez el 18 de marzo de 1933. Con un tiraje de

${ }^{30}$ Entrevista a Francisco Lucrécio, en Quilombohoje, op. cit., p. 40.

${ }^{31}$ Entrevista a Marcello Orlando Ribeiro, en Quilombohoje, op cit., p. 87.

${ }^{32}$ Santos Gomes, op. cit., pp. 54 y 55.

${ }^{33}$ Entrevista a Francisco Lucrécio, en Quilombohoje, op. cit., p. 42. 
1000 a 5000 ejemplares, fue el medio que utilizó para difundir las ideas de la organización. El objetivo de $A$ Voz da Raça, consistió en abordar el problema del racismo no sólo denunciándolo, sino además “aproximar a los sectores de la población negra a una organización que manifestaba deseos, intenciones y expectativas más amplias de ciudadanía y participación". ${ }^{34}$

El área jurídico-social se encargó de defender a sus miembros cuando sus derechos civiles eran violentados. El doctrinario fue el departamento responsable de la formación cívica, a través de cursos, conferencias y orientación ciudadana para sus miembros. A partir de esas enseñanzas, los nuevos miembros comenzaron a entender eventos que les habían ocurrido en diferentes etapas de su vida. Como explica Francisco Lucrécio: "Yo fui percibiendo porque había pasado por ciertos problemas, fui entendiendo las situaciones relativas al negro". ${ }^{35}$

El denominado Departamento de Colocación de Domésticas buscó garantizar la introducción de las mujeres frentenegrinas en el campo laboral y proteger sus derechos de trabajadoras. La defensa a las trabajadores domésticas fue muy importante, pues frecuentemente fueron tratadas como esclavas por sus patrones, muchos de ellos, las tenían en un verdadero cautiverio laborando todo el día, en ocasiones sin alimento o sueldo. Algunas más sufrían toda clase de maltrato sexual y físico. Otros patrones declaraban que la doméstica, al ser casi parte de la familia, no tenía porqué recibir ningún salario, entre otras cosas. ${ }^{36}$ Por lo tanto, ese Departamento surgió ante las constantes violaciones de los patrones a los derechos de las domésticas, uniéndose al trabajo de los primeros sindicatos y a las nuevas leyes decretadas a favor de los trabajadores.

Los otros departamentos fueron el médico; artes y oficios; musical; deportivo y el teatral. Contrario a la "prensa negra", FNB contó con una

${ }^{34}$ Santos Gomes, op. cit., p. 53.

${ }^{35}$ Entrevista a Francisco Lucrécio, en Quilombohoje, op. cit., p. 36.

${ }^{36}$ Un testimonio de esta situación fue el de la doméstica Ana, quien denunció a la policía a su patrona, declarando que: "Hace muchos años ya no le era permitido salir a la calle por los dueños de la casa, ni siquiera acompañando a la familia. No tenía licencia de llegar a la puerta de la calle. No era bien tratada en la casa de Júlio Ramalho, sufriendo 
amplia participación de las mujeres. Ellas formaron el grupo Rosas $\mathrm{Ne}$ gras, encargado de los trabajos asistenciales y de la organización de diversos eventos, entre ellos los bailes. Estos últimos buscaron propiciar la autoafirmación como negro tanto de forma individual como grupal.

Una de las mayores aportaciones de FNB fue proponer que los afrobrasileños debían ser parte activa de la política brasileña y no sólo sujetos pasivos. FNB insistió en la integración política porque a partir de ahí se alcanzaría tanto la integración social como económica. ${ }^{37}$

Sustentado en la idea que "sólo cabía al propio negro cuidar de su integración en la sociedad de la época, adecuándose a las exigencias del mundo moderno", ${ }^{38}$ impulsó y asesoró la compra de terrenos en la periferia de la ciudad con la idea de construir casas propias. Esta acción fue importante, pues además de convertirse en propietarios, les permitió mejores condiciones de vida, dado que la mayoría de los negros vivía en cobertizos en condiciones precarias e insalubres. ${ }^{39}$

Al interior de FNB existieron desacuerdos debido a la diversidad de ideologías. Esas tensiones provocaron cismas dentro del grupo. Por un lado, se encontraron las ideas defendidas por Arlindo Veiga dos Santos, quien era integralista (versión brasileña del fascismo europeo con xenofobia). Veiga dos Santos, primer presidente de FNB, publicó sus ideas en

\footnotetext{
allí castigos por parte de la mujer de aquel ciudadano, Fabrícia Ramalho. Era castigada con un chicote, recibía bofetadas, golpes en la espalda y brazos, de los cuales, en consecuencia de esas gravísimas golpizas, tenía dificultades para poder erguirse hasta la altura de la cabeza. Que Fabrícia Ramalho, además de golpearla constantemente, le daba de bofetadas en la boca, con las cuales le arrancó los dientes. Citado en Domingues, "Uma história não contada...", p. 249.

${ }^{37}$ Albuquerque y Fraga Filho, op. cit., p. 265.

${ }^{38}$ Loc. cit., p. 265.

${ }^{39}$ En 1926 el higienista Geraldo de Paula Sousa describió en su informe que el barrio Santa Ifigênia, uno de los barrios de mayor concentración de negros, poseía 116 cobertizos, con 806 cuartos, en las cuales vivía una población de 2358 personas. Dichos cobertizos no contaban con el mínimo de 10 metros cuadrados y servían para albergar de 3, 4 y más personas. Muchos de ellos no poseían ventanas, apenas 9 tenían un baño, lo que daba la media de 262 personas por baño. Citado en Domingues, "Uma história não contada...", pp. 216 y 217.
} 
el periódico Pátria Nova. Religião, Pátria e Raça, del cual era director y responsable, editado por el Centro Monarquista de Cultura y Política. ${ }^{40}$ La influencia de este grupo se reflejó, por ejemplo, en la formación de la milicia de FNB. Pero estas ideas no fueron compartidas por todos los frentenegrinos y provocó grupos disidentes.

El primer cisma ocurrió en 1932 con la formación del Club Negro de Cultura Social, dirigido por Correia Leite. La segunda, también en 1932, Guaraná Santana fundó el Partido Radical Nacionalista (PRN), con ideología ultranacionalista, teniendo como modelo el fascismo europeo. $\mathrm{Su}$ propósito fue asegurar la unión político-social de los descendientes negros en Brasil y con esta idea formó la Legión Negra. ${ }^{41}$

La última escisión fue en junio de 1933 cuando surgió Frente Negra Socialista, liderada por Manoel dos Passos. Este grupo, según José Correia Leite, era "un grupo de izquierda, que formaba parte de FNB, pero cuando vieron que las ideas de Isaltino y Arlindo Veiga dos Santos estaban prevaleciendo, que era un negocio de derecha, entonces ellos salieron [...] sólo que no consiguieron desarrollarse". ${ }^{42}$

Algunos grupos no rompieron con FNB, pero apoyaron otros ideales, como fue el caso del núcleo formado en Santos, quienes apoyaron al Partido Socialista en las elecciones y mantuvieron estrechas relaciones con el Sindicato Portuario. ${ }^{43}$

Más allá de las rupturas al interior de FNB es importante destacar la actuación y participación de la comunidad negra en las diferentes trincheras políticas, ya sea apoyando el nacionalismo o el comunismo. Lo importante fue la transformación del negro como actor activo dentro de los debates políticos que se gestaron en la época.

La relación de FNB con Getulio Vargas fue, desde la Revolución de 1930, de abierto apoyo. FNB elogió constantemente al régimen debido a sus acciones de sensibilidad frente a la comunidad negra y por concordar

\footnotetext{
${ }^{40}$ Santos Gomes, op. cit., p. 59.

${ }^{41}$ Domingues, “A Nova...”, pp. 66 y 130.

${ }^{42}$ Entrevista a José Correia Leite, en Quilombohoje, op. cit., p. 70.

${ }^{43}$ Santos Gomes, op. cit., p. 60.
} 
con él sobre un proyecto político autoritario y nacionalista. De hecho, el propio Arlindo Veiga dos Santos se manifestó continuamente contrario a la democracia, inclinándose por el régimen fascista europeo. ${ }^{44}$

La relación de Vargas con Frente Negra fue, en tanto no cuestionara sus decisiones, de apoyo a los negros. En 1931, Vargas decretó la Ley sobre la Nacionalización de los Trabajadores, en la cual señaló que las industrias debían contar en su nómina con dos tercios de trabajadores nacionales por lo menos. Esta política antiinmigratoria buscó una integración étnica. FNB percibió en esta ley un logro importante, dado que uno de sus objetivos era la búsqueda de relaciones laborales más equitativas, sector en el que era más evidente el prejuicio racial. ${ }^{45}$

La simpatía de FNB por Getúlio Vargas se incrementó cuando en la Constitución del 16 de junio de 1934 se estableció en su Título III, Capítulo II, "la igualdad de los ciudadanos no habiendo privilegios, ni distinciones debido a nacimiento, sexo, raza, profesión, clase social, riqueza, creencias religiosas o ideales políticos". ${ }^{46}$

La empatía entre el régimen y FNB se reflejó en su apoyo en la represión política del gobierno, ofreciendo información o solicitando permisos para la realización de algún evento, al cual eran también invitados funcionarios del régimen. A pesar de esto, el Departamento de Orden Política y Social inspeccionó e incluso infiltró agentes policiales en las reuniones de la organización. ${ }^{47}$

Lo anterior fue una consecuencia que, a pesar de las supuestas muestras de cordialidad, Vargas sostuvo las ideas de la medicina legal dentro de la legislación penal. Ésta consideraba a los negros como "razas inferiores [que tendían a] la impulsividad primitiva, fuente y origen de los actos violentos y antisociales [las que] por mucho predominaban sobre las

${ }^{44}$ La defensa por el nacionalismo y su autoidentificación como brasileño, relegando el concepto de afrodescendiente, puede explicarse en dos sentidos, primero por el fuerte sentimiento antiinmigrante y en segundo, a que en esa época se generó un discurso negativo en contra de África.

${ }^{45}$ Albuquerque y Fraga Filho, op. cit., p. 266.

${ }^{46}$ Davis, op. cit., p. 35.

${ }^{47}$ Domingues, “A Nova...", pp. 67 y 68. 
acciones reflexivas y adaptadas, que sólo se hacen posibles, en las razas cultas y en los pueblos civilizados" ${ }^{48}$ Con ésta lógica, todas las acciones de prevención y represión al crimen seguían teniendo como principal sospechoso al negro.

En el año de 1932, el gobierno de Vargas fue confrontado por la revolución constitucionalista de São Paulo. FNB trató de mantenerse al margen de la situación imperante en la política brasileña, pero fue sacudido por la separación de un grupo de frentenegrinos que, al mando de Joaquín Guaraná de Santana, apoyó a los revolucionarios a través de la Legión Negra de São Paulo o Pérolas Negras.

En 1932, Vargas recibió a una comisión de Frente Negra, que solicitó el ingreso de negros a la Guardia Civil, la que hasta entonces estaba compuesta de blancos y extranjeros. La autorización del régimen permitió que FNB alistara a 200 negros en la Guardia Civil de São Paulo. Esto fue una oportunidad para los miembros que se enlistaron y un triunfo en los objetivos de FNB. Según comenta Marcello Orlando Ribeiro, quien ingresó a la Guardia Civil en ese entonces, que "esos negros [...] tuvieron la oportunidad de poner a sus hijos a estudiar en escuelas, colegios y otros negros pudieron construir su casa propia o adquirir alguna propiedad". 49

Sin embargo, la decisión de Vargas de aceptar el ingreso de los frentenegrinos en la Guardia Civil ocurrió después de la derrota de la revolución de 1932, cuando sus tropas ocuparon São Paulo. Esto no fue una coincidencia. La fidelidad de los líderes de FNB hacia el régimen era conocida, por lo que desde una perspectiva de estrategia política, aceptar frentenegrinos en la Guardia Civil representó la seguridad del propio régimen en un momento de tensión política.

En 1933 FNB lanzó como candidato a la diputación paulista a su presidente Arlindo Veiga dos Santos, quien expresó el repudio a la onda mi-

${ }^{48}$ Raimundo Nina Rodrigues, As Raças humanas e a responsabilidade penal no Brasil, $3^{\mathrm{a}}$ ed. (1 $1^{\mathrm{a}}$ 1894), Río de Janeiro, Biblioteca Pedagogica Brasileira, 1938, pp. 115 y 116. ${ }^{49}$ Entrevista a Marcello Orlando Ribeiro, en Quilombohoje, op. cit., p. 84. 
gratoria y la defensa de la tierra para los brasileños. Frente a este discurso surgió la candidatura de José Bento de Assis, quien no sólo se mostró más conciliador, sino además expresó la necesidad de una segunda abolición para el negro. ${ }^{50} \mathrm{El}$ resultado electoral no favoreció a la comunidad negra. Pero exhibió una gran movilización de los negros, demostrando que también ellos podían ser protagonistas dentro de la política brasileña.

En Recife (1934) y en Salvador de Bahía (1937) se realizaron, respectivamente, el I y II Congreso Afrobrasileño. En estas reuniones se buscó que los cultos africanos fueran reconocidos, al tiempo que se organizó “A União de Seitas Afro-brasileiras de Bahía”. Declararon "que cada pueblo [tenía] su religión, su forma de adorar a Dios - y el "candomblé" [era] la organización religiosa de los negros esclavos y hombres de color de Bahía que [era] una herencia de los africanos". ${ }^{51}$

En 1937 fue fundado el Centro de Cultura Afrobrasileña, que buscó impulsar investigaciones sobre la cuestión de la comunidad de descendencia africana en Brasil. En ese escenario de constante actividad, FNB consideró la posibilidad de convertirse en un partido político. Los promotores de esta idea fueron acusados de separatistas. Sin embargo, en 1936 lograron reunir los requisitos solicitados por la Justicia Electoral.

La idea era tener un partido político que representara la causa del negro. Fue el tiempo de mayor fuerza política de FNB, al grado de ser un grupo con el que los grandes políticos deseaban entablar diálogo para conseguir su apoyo. Como recuerda Arístides Barbosa: “en aquellos tiempos los grandes políticos de la época iban a negociar [...] iba Ademar de Barros, Armando Salles de Oliveira, Pedro Toledo; los políticos prominentes. Ellos iban a pedir apoyo de un partido fuerte [... ${ }^{\prime}{ }_{52}$

\footnotetext{
${ }^{50}$ Santos Gomes, op. cit., p. 63.

${ }^{51}$ María do Rosario de Fátima Andrade Leitao, "Movimiento negro en Brasil”, ponencia dictada dentro del VI Encuentro de Latinoamericanistas Españoles, p. 4. En http:// www.ucm.es/info/cecal/ encuentr/areas/antropol/2a/andrade (fecha de consulta: 2 de marzo, 2007).

${ }^{52}$ Entrevista a Arístides Barbosa, en Quilombohoje, op. cit., p. 25.
} 
Al siguiente año, Vargas acusó a los comunistas de una conspiración y proclamó un golpe de Estado que dio origen al Estado Novo. Ese periodo se caracterizó por la dura represión del gobierno, el cual prohibió la existencia de todas las organizaciones políticas, entre ellas Frente Negra Brasileña.

Algunos miembros de FNB buscaron, a pesar de las circunstancias, revitalizar una organización y formaron la Unión Negra Brasileña. Pero el cierre de FNB golpeó el ánimo de la comunidad negra, al reflejarse en una escasa participación. Dada su fragilidad, se convirtió en el Club Recreativo Palmares que se dedicó a actividades recreativas.

Sin duda, FNB fue el movimiento urbano más importante de la época en la movilización del negro en su lucha por su inclusión social y política en Brasil. Logró superar la idea de "hombre de color", que como señaló Florestan Fernandes era un término vacío, para autorreconocerse como negro. ${ }^{53}$

Si bien FNB no buscó una revolución en el sistema, sino la integración del negro dentro de la sociedad, debe reconocérsele su lucha por conseguir mejores condiciones de vida para la comunidad negra, la constante crítica y movilización contra los prejuicios de color, así como su innovadora idea de introducir al negro como actor activo dentro del escenario político brasileño.

Es necesario indicar que las diferentes sedes de FNB no tuvieron el mismo escenario político-social que el presentado en São Paulo. El desarrollo de las representaciones frentenegrinas en otros estados tuvo una dinámica propia. Por ejemplo, en Bahía.

Frente Negra de Bahía, creada en 1932, bajo la dirección de Marcos Rodrigues dos Santos, hizo sentir su influencia en la formación de los estatutos y en la dinámica que se le imprimió a la organización, debido a que en su carrera profesional tuvo contacto con los movimientos y ac-

${ }^{53}$ El propio Florestan Fernandes señala que fue Vicente Ferreira el primero en hacer la sustitución de "hombre de color" por "negro". Florestan Fernandes, A integração do negro na sociedade de classes. No limiar de uma nova era, São Paulo, Universidade de São Paulo, Dominus Editôra, 1965, vol. II, p. 15. 
ciones emprendidas en São Paulo. De esta manera, FN de Bahía trazó los mismos objetivos que FNB. Sin embargo, los contextos sociales cambiaron considerablemente, haciendo la diferencia tanto en el impacto como en el tiempo de existencia de la organización.

La primera diferencia con São Paulo es que en Bahía FN fue fundada por mestizos y mulatos de condición muy modesta, contando con la participación de una pequeña clase trabajadora. En Bahía, la lucha de los trabajadores tenía una historia de fuerte represión, especialmente en la década anterior. Aunado a que Bahía atravesaba por un momento de crisis económica y alto desempleo. Por lo que FN de Bahía fue utilizada para exponer las insatisfacciones de los trabajadores, por lo que "la cuestión racial aunque aparentemente adormecida tocaba fondo en el contingente mayoritariamente de la clase trabajadora". ${ }^{54}$

En Bahía, "los descendientes de esclavos no [fueron] desalojados de sus posesiones en el mercado de trabajo, algunos mestizos se integraron al mundo de los blancos y muchos mulatos, sobre todo en el trabajo autónomo, alcanzaron modesta, pero estable condición material". ${ }^{55}$ Esto refleja la primera diferencia con São Paulo, en donde los inmigrantes desplazaron a los afrodescendientes de sus centros de trabajo y sus condiciones de vida fueron, en la mayoría de los casos, precarias.

Otra diferencia es que en Bahía hubo mínimas transformaciones con la Revolución de 1930. En Bahía, ni el trabajo asalariado ni la rápida industrialización fueron características que correspondieran a su dinámica. Tampoco existió una alta inmigración europea como ocurrió en São Paulo y, en consecuencia, no hubo un ambiente hostil en contra de éste. Por tanto, dentro del grupo afrodescendiente, no se generaron los elementos necesarios para fortalecer una organización como FNB.

En una sociedad como la bahiana, "la realidad del mito de la democracia racial era incuestionable, no habiendo así motivo para que las per-

${ }^{54}$ Jeferson Bacelar, "Frente Negra Brasileira na Bahia”, Afro-Ásia, núm. 17, Centro de Estudos Afro-Orientais-UFBA, 1996, p. 81.

${ }^{55}$ Ibid., p. 79. 
sonas se agruparan en función de su color". ${ }^{56}$ Por lo que la identificación por el color de la piel no fue un elemento aglutinador. Si bien, no existió una represión directa en contra de FN de Bahía, sí se generó una enorme presión de parte de los no negros e incluso de algunos negros, en contra de la idea de deslegitimar la supuesta cordialidad entre los diferentes grupos en la sociedad. La ideología sobre la supuesta excepcionalidad racial en Brasil, estaba fuertemente cimentada en la sociedad bahiana.

Sin embargo, cuando FN en Bahía lanzó la idea de formar un partido político, los trabajadores reavivaron un deseo que había sido cooptado con anterioridad. Este elemento hizo que tomara un poco de fuerza la organización, lanzando a su primer candidato como representante único para la Cámara Federal, el 31 de marzo de 1933. Sin embargo, las presiones del poder político hicieron que retiraran la candidatura. ${ }^{57}$

Como se observa, cada vez más FN de Bahía fue absorbida por los intereses y objetivos de los trabajadores, más que por una acción en contra del prejuicio de color. Lo que finalmente desencadenó la desaparición de la organización, al ser absorbida por los trabajadores y pequeños sindicatos.

Las diferencias visibles entre el proceso que se desarrolló en São Paulo y en Bahía evidencian la heterogeneidad de condiciones políticosociales en las diversas regiones brasileñas, lo cual genera distintos escenarios, problemáticas y formas de abordar el mismo objeto de estudio. Esta comparación, además puede alumbrar el hecho de que en Brasil no se hubiese podido constituir desde ese tiempo hasta el presente, un movimiento único de alcance nacional que tenga objetivos, fundamentos $\mathrm{y}$ acciones conjuntas.

\section{CONCLUSIONES}

La combatividad de los afrobrasileños no terminó una vez decretada la abolición de la esclavitud, sino que ésta se modificó y adecuó frente a los nuevos obstáculos que se presentaron.

\footnotetext{
${ }^{56}$ Ibid., p. 80.

${ }^{57}$ Ibid., p. 83.
} 
Las diversas agrupaciones surgidas en el periodo de la "prensa negra", así como Frente Negra Brasileña estuvieron fuertemente influidas por los actores políticos-sociales que se encontraban en torno a ellos y del contexto político-social-ideológico de su tiempo. En este sentido, la "prensa negra" se inspiró en los esquemas y objetivos de las publicaciones de los migrantes, trabajadores y grupos anarquistas. Pero por otro, también proyectó las contradicciones latentes entre el discurso hegemónico que pregonaba la existencia de relaciones cordiales entre los diferentes sectores de la sociedad y la realidad cotidiana a la que eran obligados a enfrentar. De esta forma, estos periódicos generaron los primeros espacios para cuestionar las estructuras sociales brasileñas, lo cual fue de gran importancia para el desarrollo de las ulteriores organizaciones afrobrasileñas.

Tanto la "prensa negra" como Frente Negra Brasileña reflejaron la existencia de una llamada "élite" negra y de una "plebe" negra. Si durante el periodo de la "prensa negra", la "élite" y la "plebe" estuvieron alejadas; durante el periodo de FNB, la comunidad negra paulista pudo unirse en contra del prejuicio y en la lucha por mejores condiciones de vida.

La organización FNB también ilustró cómo los diferentes procesos históricos vividos entre las regiones impactan en que las organizaciones tengan desiguales repercusiones en sus ámbitos de acción, como ocurrió en la comparación entre São Paulo y Bahía. Lo anterior me permite afirmar que la gran diversidad de organizaciones, fines, alcances y duración, sea una de las razones por las que no se ha podido construir, desde ese momento hasta el día de hoy una organización afrobrasileña que conjugue todos los intereses de las diversas regiones que componen Brasil.

Finalmente, a pesar de los diversos objetivos y distintas organizaciones, el común denominador de todas ellas es la lucha por su verdadera incorporación en la sociedad brasileña, haciéndole frente, desde diversas estrategias, a una ideología hegemónica que se crea y recrea en el tiempo argumentando la inexistencia del racismo en Brasil. 


\section{BIBLIOHEMEROGRAFÍA}

Albuquerque, Wlamyra de y Walter Fraga Filho, Uma história do negro no Brasil, Salvador, Centro de Estudios Afro Orientales-Fundação Cultural Palmares, 2006, 318 pp.

BACELAR, Jeferson, "Frente Negra Brasileira na Bahia", Afro-Ásia, núm. 17, Centro de Estudos Afro-Orientais-UfBA, 1996, pp. 73-85.

Davis, Darien J., Afro-brasileiros hoje, São Paulo, Selo Negro, 1999, $125 \mathrm{pp}$.

De Fátima Andrade Leitao, María do Rosario, "Movimiento negro en Brasil", ponencia dictada dentro del VI Encuentro de Latinoamericanistas Españoles. En http:/www.ucm.es/info/cecal/encuentr/areas/ antropol/2a/andrade (fecha de consulta: 2 de marzo, 2007).

Del Priore, Mary y Renato Pinto Valencia, O livro de ouro da História do Brasil, Río de Janeiro, Ediouro, 2001, 407 pp.

Domingues, Petrônio, Uma história não contada. Negro, racismo e branqueamento em São Paulo no pós-abolição, São Paulo, Senac, 2004, $400 \mathrm{pp}$

, A Nova Abolição, São Paulo, Selo Negro, 2008, 182 pp.

FERnANDES, Florestan, A integração do negro na sociedade de classes.

No limiar de uma nova era, 2 vols., São Paulo, Universidade de São Paulo, Dominus Editôra, 1965, 313 pp.

George Hanchard, Michael, Orfeu e o poder. Movimento Negro no Rio e São Paulo (1945-1988), Río de Janeiro, Universidade do Estado do Rio de Janeiro, 2001, 243 pp.

MourA, Clóvis, "Formas de resistência do negro escravizado e do Afrodescendente", en Kabengele Munanga [org.], História do negro no Brasil. O negro na sociedade brasileira: resistencia, participação, contribuição, Brasilia, Fundação Cultural Palmares, 2004.

Nina Rodrigues, Raimundo, As Raças humanas e a responsabilidade penal no Brasil, $3^{\mathrm{a}}$ ed. (1 $1^{\mathrm{a}}$ 1894), Río de Janeiro, Biblioteca Pedagogica Brasileira, 1938, 272 pp. 
Quilombohoje [org.], Frente Negra Brasileira. Depoimentos, São Paulo, Fundo Nacional da Cultura-Ministerio da Cultura, 1998, 111 pp. Read Andrews, GeOrge, Negros e brancos em São Paulo (1888-1988), São Paulo, EDUSC, 1998, 443 pp.

Santos Gomes, Flávio dos, Negros e política (1888-1937), Río de Janeiro, Jorge Zahar Editor Ltda., 2005 (Col. Descubrindo o Brasil), $92 \mathrm{pp}$.

Silveira, ReNATO DA, “Os Selvagens e a massa. Papel do racismo científico na montagem da hegemonia occidental", Afro-Ásia, núm. 23, Centro de Estudios Afro-Orientales-UfBA, 2000, pp. 87-144. 